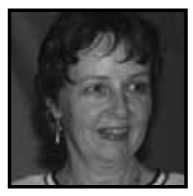

\title{
Commentary
}

\section{Fostering a New Approach to Understanding: Learning Through Intent Community Participation}

\author{
Barbara Rogoff
}

\begin{abstract}
In this interview, author Barbara Rogoff describes an informal learning practice called "intent community participation." This type of learning occurs when children are included in a wide range of community activities and observe, contribute, and receive support and feedback from others. She describes the advantages and challenges of intent community participation and examples of how it might be integrated in schools. Finally, Dr. Rogoff gives us her thoughts on how to foster this kind of orientation to learning in teacher preparation.
\end{abstract}

I believe there are some interesting links between your extensive work in apprenticeship thinking and informal learning. Can you talk a little bit about this?

became very interested in informal learning quite early when I was a grad student and especially when I went to work on gathering data in a Mayan community in the highlands of Guatemala. I noticed how skilled the children were in a number of different things and I asked their mothers, "How do you teach them?" And the mothers said generally, "We don't teach them, they learn." I thought "I have no way of understanding that" because I was thinking that people learn by being taught, so how do people learn in situations when nobody's teaching them?

That led me into trying to understand what people are doing to help children learn in situations where it's not teaching, and by "teaching" I think that the Mayan mothers meant the kind of teaching that goes on in school, and I think that's 
what I meant at the time too. There's lots of ways of assisting learners that are not what we were calling "teaching" and learners bring to bear themselves quite a bit of expertise in going about learning in situations where it's not structured like teacherlearner.

That's very closely related to informal learning which has a history in anthropology looking at small communities like the Mayan community I was working in; children learning by observing and pitching in to what's going on in the community, documented in many ethnographies. It has been called "informal learning."

More recently informal learning has become of interest, especially in the museum world, trying to understand how people in museums can be learning when it's not a didactic setting. I've been trying to open the idea of informal learning into something that's not just a dichotomous opposition to what goes on in school-so it's not formal learning versus informal learning. There are many different kinds of informal learning. I think we should be trying to understand the different kinds that are available as alternatives to some forms of learning that happen in school that we know are not very effective, and even connecting up some kinds of learning that happen in school that are effective that may connect up with informal ways of learning.

\section{Can you tell us a few examples of the different kinds of informal learning?}

One that's often used in the museum world is "inquiry learning," which is quite interesting. But the one I have most focused on in my research has been what I call "learning through intent community participation," which is for children to be involved in activities in their community and helping out and doing so under their own initiative but also with the support of other community members. They are observing keenly what's going on and contributing from a very early age already as participants in the community rather than being seen as people who are not yet ready to be a part of the community. They're part of the community from the beginning. How do they learn: by observing, by contributing. What are the aspects that are important to being able to learn in that form of informal learning-that's been the central question of my research.

\section{Do you have some specific examples that stand out for you?}

It's widespread in the Mayan community where I've been working for the 
children to be a part of what's going on and for them to be keenly aware of what's going on around them. They might be playing with a particular toy and at the same time they're listening in on conversations around them, they're alert to something interesting happening across the way. They are alert to learn from a number of surrounding events that they may be directly participating in or in the presence of. They can learn by being alert and by being ready to help out without being asked, which seems to be a part of this way of learning. That alertness, the initiative that's involved in helping out, the skill in collaboration which is involved if you're pitching into community or family activities and the consideration that's needed to be able to take the perspective of other people and coordinate with them. Those are all aspects of what we see in my research group as learning through intent community participation.

Learning through intent community participation has been widespread in the Mayan community where I've worked-I talk about that in my new book, "Developing Destinies: A Mayan Midwife and Town," which just came out. It focuses on changes and continuities in practices like learning through intent community participation.

I should clarify one thing: it has been traditional for the children to be learning through intent community participation; they still do but there are enough changes in children's lives in the Mayan community and actually worldwide that there are now fewer opportunities for them to be present and involved with the wide range of activities in their communities. There's a lot of ethnographies in other Indigenous communities of North and Central America where the same way of learning is very common, and there's probably ways of learning that are similar in other parts of the world. But we are hesitant to generalize without knowing more about how they really function. We don't want to jump into over-generalizing...more research needs to be done in different parts of the world before we can say whether it's similar on other continents or different.

\section{What are the advantages of learning through intent community participation?}

Learning through intent community participation has a number of advantages compared with the kind of "assembly-line instruction" that is common in schools. (But of course assembly-line instruction is not necessarily how schools run.) Compared with assembly-line instruction, learning through intent community participation encourages children's initiative; it encourages children to be attentive to what's going on around them, to make sense of things on their own and with the help 
of others, to be planning, because they are able to contribute. If something arises that might be an obstacle...they have to figure out how to go around it. There's many opportunities to be building one's understanding plus if children are in the presence of other people working on similar aspects of the same activities, they have a chance to observe how other people handle similar issues. So they don't have to discover it all on their own, but they are very active in watching what others do, trying things themselves, using initiative to be a part of the larger endeavour.

\section{Are there any challenges to this kind of learning?}

If children are not allowed to be present it's more difficult for them to be learning in that way. Children in countries that require them to be segregated from the wide range of activities of the community for many hours of the day-such as in formal schooling - they have fewer opportunities to be helping out, pitching in, learning by observing people in the productive and social activities of their communities.

A challenge would be if we were trying to implement learning through intent community participation more broadly in children's lives in the United States, we would have the impediment that they are often excluded from situations where they can use that kind of learning. However, I should point out that even in highly schooled communities in the United States, children learn a lot through intent community participation, including how everybody learns their first language: by listening in and watching how other people use it, having something to say, trying it out, contributing to conversation or other ongoing events.

Another example would be even in schools that might be run through assembly-line instruction, children are seldom instructed in how to do their part in assembly-line instruction. They learn that in the process of being embedded and contributing to the ongoing activity of assembly-line instruction, through observing and contributing. Even in schools that are run in the assembly-line instruction way, they would be using intent community participation to figure out what are the rules, how to get a turn, who gets favoured... all the kinds of hidden curriculum of the school.

Of course, many schools are doing things differently than assembly-line instruction. For about ten years I studied a school in Salt Lake City, which I refer to as the "OC." I've written a book together with parents, teachers, the principal, and children of that school called, "Learning Together: Children and Adults in a School 
Community." In that book we built on what we learned from being a part of a school that's run more collaboratively, much like learning through intent community participation, to talk about what's involved for adults and children to collaborate in classroom situations. That was a difficult thing for many adults who were volunteers in the school to learn how to do; difficult for some new teachers; not difficult for the children. I wanted to underline that there are schools that are doing things that are fairly much aligned with learning through intent community participation, and if people are interested in learning more about the principles involved in that, that would be by looking at the book, "Learning Together: Children and Adults in a School Community," which is Oxford 2001.

\section{Can you tell us a little bit about how that school functioned?}

It's a public school, kindergarten through sixth grade (now through eighth). Parents need to volunteer for their children to be in the school; they volunteer three hours a week in the classroom. It's a public school, sort of a magnet school, and doesn't cost the school district any more than the regular neighbourhood school. The parents generally want something different for their children than what their neighbourhood school offers. Some of them are eager to be volunteering in the classroom. Others, like me, I was a parent-volunteer there because I wanted my children to have the opportunity to be part of it.

I didn't understand the philosophy of the school when my children began there. Over time, after some struggles on my part, in fact, I came to see that the central part of the philosophy was that the children and the adults were collaborating on creating learning situations for the children, and that also involved learning situations for the adults. That was a necessary part of creating a community of learners that worked for the children and for the adults. Curriculum was developed by children and adults together, and children had an understanding of why they were learning what they were learning.

Often the learning involved developing a project that was of interest to everybody, the children and the adults alike, that would carry with it learning of some of the curriculum topics that were part of the state-wide core curriculum. For example, there was a fourth- and fifth-grade classroom that was studying probability and they decided to make a "Las Vegas" day where they were going to play games of chance. The adults wore those kinds of visors that the casino people in Las Vegas wear and they played at "Las Vegas"... While they were playing these games of chance, the 
principal came along and said, "What's going on here?" And the children said: "Oh, we're studying probability; it's part of the state core curriculum." They were having fun playing these games of chance and at the same time they knew that they were learning probability and they were thinking of it reflectively and with interest. The curriculum was carried by the collaborative interest of the adults and the children.

There is always interest in how to deal better in teacher preparation and professional development as well. What would you suggest to foster this kind of orientation to learning?

One of the things that's most important for adult learning is the same as for children's learning: for people to be involved and participating, having a chance to observe others, having a chance to contribute. I try to organize my undergraduate and graduate classes in ways that are somewhat aligned with intent community participation, though it's a challenge sometimes to do so.

I think one of the hardest things for new teachers is that most of their instruction has occurred in ways that are not what we want them to do themselves. New teachers, like anybody else, have learned a lot by the situations in which they have been participants. Their chemistry class or their high school English class-however they have been embedded in learning for their whole lives-those are part of what they come into teacher preparation programs understanding. And like the struggle that I had as a new parent in the school in Salt Lake City, you have to kind of be able to open up your eyes to a different way of doing things, and sometimes that means letting go of what you're familiar with-which is a challenge.

Kris Gutiérrez, who is past president of the American Educational Research Association, has done a number of projects in which she has teachers watch children in more than one setting. For example, they might follow a particular child in the classroom and then in an after-school setting. Kris has organized some after-school settings that are very effective situations for the children's learning. The teachers have a chance to see that the same child may act quite differently when they have a chance to be contributing with interest than they do in a classroom where they're simply told what to do and have to sit still all day. The teachers get to see a contrast that opens their eyes. For that question, I think maybe some of the best answers are found in the work of Kris Gutiérrez. 
Do you have any particular story that you would like to share with us about this approach to learning?

One example of this approach to learning that I think is very compelling is one of my kids is now a software engineer in a prominent company. She learned how to program computers through intent community participation. As an undergraduate she didn't study anything resembling computer programming. She studied biology, anthropology, Latin American studies, and then after she graduated she met some friends who were involved in technology and she helped them out. And they created a start-up together, and in the process she learned how to program.

She was learning by pitching in-she had the guidance of her friends who were already skilled in that area. It was interesting to her partly because of the social relations with the friends, and partly because it was just interesting. So now she is a very skilled employee of a prominent company, and her learning is quite different than a student who goes through a computer science program for the most part, at least that's what I hear. She says that when she's interviewing for a job she needs to study some of the things that are perhaps emphasized in a university computer science program because she'll be tested on those in an interview, but they're not needed for being a programmer. What's needed to pass a test, an academic test, even in industry, is different than what's needed for her to be a very skilled programmer, a leading programmer in her work. The basis of her understanding came from learning through intent community participation.

That's a wonderful story and I think it really brings to the forefront how our digital age is maybe forcing some of that to happen. In virtual communities there seems to be much more of that kind of approach to acquiring new understandings and new skills. Would you like to add anything else?

The idea that there may be some changes afoot with digital technologies that may open up learning through intent community participation is a really important one. Video and interactive animation simulations of various sorts now allow people to be sort of present for the activities that are ongoing. For instance, if I were to try to explain to you in a class "How do you weave?" or "How do you program?" I would have to give lots of definitions, long explanations... You'd have to be trying to visualize it yourself; you wouldn't be able to see the process. But with the aid of video clips or other ways of giving people more of a presence in the activity, we don't need lengthy explanations out of the context of the activity. People can sort of just see it. 
In my talks that I give at national conferences and so on, I use a lot of video clips now and people understand the research phenomenon at a much deeper level than when I used to just try to talk them through it and tell them both principles and examples. The principles can be shown and illustrated with the examples in a way that begins to resemble learning through intent community participation with the aid of representations that are sometimes interactive, and used more as a means of communication than simply explanations out of context, which schools were dependent on for many years. I think that there is a real chance for change in our ways of supporting people's learning, with the changes of our technologies. But they will require also having a deeper understanding of ways of supporting learning, such as intent community participation, and other alternatives to assembly-line instruction.

\section{References}

Rogoff, B. (1991). Apprenticeship in thinking: Cognitive development in social context. New York: Oxford University Press.

Rogoff, B. (2003). The cultural nature of human development. New York: Oxford University Press.
Rogoff, B. (2011). Developing destinies: A Mayan midwife and town. New York: Oxford University Press.

Rogoff, B., Goodman Turkanis, B., \& Bartlett, L. (2001). Learning together: Children and adults in a school community. New York: Oxford University Press. 


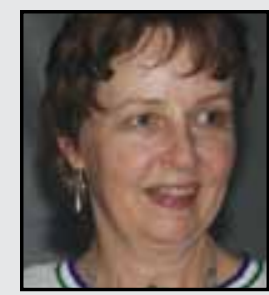

Barbara Rogoff is UCSC Foundation Distinguished Professor of Psychology. She is a Fellow of the National Academy of Education, Association for Psychological Sciences, American Anthropological Association, American Psychological Association, and American Educational Research Association. She has been Fellow of the Center for Advanced Study in the Behavioral Sciences, Kellogg Fellow, Spencer Fellow, and Osher Fellow of the Exploratorium. She has served as Editor of Human Development and committee member on the Science of Learning for the U.S. National Academy of Science. Recent books include "Learning Together: Children and Adults in a School Community" (Oxford, 2001), "The Cultural Nature of Human Development" (Oxford, 2003), and "Developing Destinies: A Mayan Midwife and Her Town" (Oxford, 2011).

LINKTO:

http://www.facebook.com/barbararogoffpublications 